\title{
PROTOTIPE SISTEM PERINGATAN DINI BERBASIS SMS UNTUK MENDETEKSI KENAIKAN KADAR GAS AMONIAK DI PENGOLAHAN AIR LIMBAH INDUSTRI PENYAMAKAN KULIT
}

\section{PROTOTYPE OF EARLY WARNING SYSTEM BASED ON SMS TO DETECT THE RISING LEVEL OF AMMONIA GAS IN WASTEWATER TREATMENT OF LEATHER TANNING INDUSTRY}

\author{
Wahyu Pradana Arsitika dan Rihastiwi Setiya Murti \\ Balai Besar Kulit, Karet dan Plastik, Yogyakarta \\ Email: wpradana@gmail.com \\ Diterima: 11 April 2013 Revisi: 27 Juni 2013 Disetujui: 29 Juni 2013
}

\begin{abstract}
The objective of this research was to produce prototype of an early warning system based on SMS for detection the rising level of ammonia gas in wastewater treatment of leather tanning industry. The systems consist of three parts, those were data input, data processing, and output. Ammonia gas sensor as a detector that produces an analog Direct Current (DC) voltage. Analog to Digital Converter (ADC) pin on the microcontroller received an analog DC voltage to be processed. ADC readings done through the Liquid Crystal Display (LCD) while the Global System for Mobile Communications (GSM) modem was used to send Short Massage Service (SMS). This early warning system worked by determining a threshold value. SMS would be sent to hand phone number of job holder, if the ADC value exceeded the specified threshold value. Result obtained was the ammonia gas sensor model are MQ137 based on $\mathrm{SnO}_{2}$, Arduino Uno as microcontroller module based on Atmega 328P microcontroller, and General Packet Radio Service (GPRS) Shield as GSMmodem that compatible with the Arduino Uno R3 pin.
\end{abstract}

Keywords: wastewater treatment, tanning industry, amonia gas, SMS, MQ 137

\begin{abstract}
ABSTRAK
Tujuan penelitian ini adalah untuk mendapatkan sebuah rancang bangun (prototipe) sistem peringatan dini melalui SMS atas kenaikan aras gas amoniak di pengolahan air limbah industri penyamakan kulit. Sistem ini terdiri dari data masukan, pengolah data, dan keluaran. Sensor gas amoniak sebagai detektor menghasilkan tegangan listrik arus searah (DC) analog. Pin converter digital ke analog (ADC) pada mikrokontroler menerima tegangan listrik DC analog untuk selanjutnya diolah. Pembacaan ADC dilakukan melalui Liquid Crystal Display (LCD) sedangkan modem Global System for Mobile Communications (GSM) berfungsi untuk mengirimkan SMS. Sistem peringatan dini bekerja berdasarkan penentuan nilai ambang batas aras gas amoniak. Apabila pembacaan detektor melebihi nilai ambang batas aras gas amoniak yang ditentukan, maka peringatan dini akan dikirimkan lewat SMS kepada nomor petugas. Hasil yang diperoleh adalah sensor gas amoniak model MQ137 dengan bahan dasar $\mathrm{SnO}_{2}$, modul mikrokontroler berupa Arduino Uno versi R3 berbasis mikrokontroler Atmega 328P, modem GSM model General Packet Radio Service (GPRS) Shield yang sesuai dengan pin Arduino Uno versi R3.
\end{abstract}

Kata kunci: pengolahan air limbah, industri penyamakan, gas amoniak, SMS, MQ137 


\section{PENDAHULUAN}

Pencemaran udara adalah masuknya atau dimasukkannya zat, energi, dan/atau komponen lain ke dalam udara terbuka oleh kegiatan manusia, sehingga melampaui baku mutu udara yang telah ditetapkan oleh Menteri Negara Lingkungan Hidup (2010).

Gas amoniak merupakan salah satu bentuk limbah yang dibebaskan/ dikeluarkan oleh industri penyamakan kulit, disamping salinitas, material organik dan anorganik, padatan terlarut dan tersuspensi, nitrogen organik dan polutan lainnya (sulfida, krom, dan sisa garam logam beracun lainnya) (Song et al, 2004).

Melihat dampak cemaran pada udara terhadap makhluk hidup dan lingkungan, pemerintah daerah menetapkan peraturan tentang baku mutu udara terbuka dan sumber emisi tidak bergerak. Sebagai contoh Pemerintah Daerah Provinsi Jawa Timur menuangkan peraturan tersebut pada Peraturan Gubernur Nomor 39 tahun 2008. Batasan gas amoniak atau $\mathrm{NH}_{3}$ di udara terbuka yang diijinkan sesuai dengan peraturan tersebut maksimum 2 ppm atau $1360 \mu \mathrm{g} / \mathrm{m}^{3}$ udara dengan pengambilan sampel tiap 1 jam selama 24 jam (Mustaqim et al., 2010).

Terdapat banyak cara untuk pendeteksian amoniak di udara terbuka. Amoniak termasuk gas yang sangat mudah tercium oleh indera penciuman, namun pada kadar sangat rendah hidung manusia tidak dapat menciumnya (Timmer, et al., 2005). Dengan kemajuan teknologi semikonduktor, maka saat ini sudah banyak terdapat di pasaran model sensor untuk pendeteksian kadar gas dalam udara terbuka dan penggunaannya berdasarkan pada besaran listrik. Oleh sebab itu penelitian yang dapat dilakukan adalah mengkombinasikan perangkat keras yang ada untuk pembuatan rancang bangun sistem deteksi.

Karakteristik sensor gas berbasis semikonduktor dipengaruhi oleh komposisi gas yang ada di udara. Berdasarkan hal tersebut, sejak tahun 1962 telah dilakukan pengembangan pengukuran konduktivitas sensor gas menggunakan thin film atau porous ceramic of n-type semiconductor oxide seperti
$\mathrm{ZnO}$ dan $\mathrm{SnO}_{2}$ (Bendahan et al., 2003). Pada penelitian sebelumnya juga digunakan oksida seperti $\mathrm{ZnO}$ atau $\mathrm{SnO}_{2}$ sebagai sensor gas amoniak karena keduanya memiliki konduktivitas relatif tinggi. Kelebihan lainnya adalah sensitivitas tinggi, rancangannya sederhana, ringan dan murah (dit Picard et al., 1997).

Pada umumnya sensor berbasis semikonduktor memerlukan pengolahan data sebelum hasilnya ditampilkan. Oleh sebab itu dibutuhkan pengolahan data yang akurat dan tepat. Perangkat keras untuk pengolahan data dapat berbentuk mikrokontroler.

Mikrokontroler adalah komputer dalam bentuk chip tunggal, dan istilah mikro menunjukkan bentuk kecil dan kontroler menunjukkan bahwa perangkat keras tersebut dapat digunakan untuk mengontrol pada penggunaan tertentu. Contoh penggunaan mikrokontroler yaitu pada mesin cuci yang diprogram secara spesifik untuk mengendalikan siklus pencucian (Ibrahim, 2010).

Mikrokontroler adalah sebuah komputer yang dilengkapi berbagai perangkat pendukung kerjanya dalam satu rangkaian listrik (onboard). Beberapa perangkat yang umum dijumpai pada sebuah komputer, antara lain: Central Processing Unit (CPU), Random-Access Memory (RAM), Read Only Memory (ROM), serta piranti Input-Output (I/O). Hal tersebut di atas juga dapat dijumpai pada mikrokontroler (Calcutt, 2004).

Beberapa tipe mikrokontroler sudah dilengkapi dengan komponen tambahan, seperti penghitung waktu, penghitung cacah, ADC, dan lain-lain. Komponen tambahan ini menjadikan mikrokontroler sebagai pengendali terintegrasi berbentuk chip tunggal yang dapat bekerja seperti komputer besar yang memiliki hard disk, floppy disk, dan printer (Ibrahim, 2010).

Sensor gas amoniak memberikan keluaran berupa tegangan listrik analog, sedangkan mikrokontroler tidak dapat membaca tegangan listrik analog secara langsung, sehingga harus didahului oleh ADC. ADC digunakan untuk mengubah tegangan listrik analog menjadi tegangan listrik digital sehingga dapat dibaca dan diproses oleh 
mikrokontroler. Pada umumnya, kapasitas ADC yaitu 8-10 bit dengan aras kuantisasi 256-1024 (Ibrahim, 2010).

Beberapa rangkaian elektronik dibutuhkan mikrokontroler pada proses pemrograman, sehingga modul mikrokontroler digunakan. Arduino Uno merupakan salah satu open-source modul mikrokontroler berbasis Atmega 328. Fasilitas yang diberikan yaitu 14 pin I/O, 6 pin input analog, serta koneksi dengan komputer untuk pemrograman menggunakan kabel Universal Serial Bus (USB) (Teikari et al., 2012).

Untuk menjadikan mikrokontroler sebagai pengolahan data dari sensor, maka perlu dilakukan pemrograman. Pemrograman merupakan sebuah metode untuk memberikan instruksi kepada mikrokontroler cara menangani masukan data, mengolah data dan mengendalikan keluaran yang diberikan (Park, 2003).

Pemrograman Arduino Uno menggunakan perangkat lunak berbasis Integrated Development Environment (IDE). Bahasa pemrograman yang digunakan adalah bahasa $\mathrm{C}$ yang disederhanakan dan didukung dengan library untuk memudahkan proses pemrograman (Wheat, 2011).

Setelah dilakukan pemrograman, Arduino Uno dapat berfungsi tanpa harus terhubung dengan komputer (Kato, 2010). Perangkat Arduino Uno dapat dikombinasikan dengan perangkat keras lain yang berbentuk modul juga (biasa dikenal sebagai shield) (Teikari et al., 2012). Bahkan saat ini sudah dijumpai GPRS shield yang dapat dikombinasikan dengan Arduino Uno. GPRS shield berfungsi untuk menghubungkan Arduino Uno dengan jaringan telekomunikasi.

\section{BAHAN DAN METODE}

\section{Bahan Penelitian}

Bahan penelitian terdiri atas sensor gas, modul mikrokontroler, modem GSM, dan komputer. Sensor gas dengan tipe MQ137 (Semiconductor Sensor for Ammonia) yang dibuat dari tin dioxide $\left(\mathrm{SnO}_{2}\right)$. Catu daya untuk sensor MQ137 tegangan DC 5 volt. Modul mikrokontroler Arduino Uno R3 dengan basis pengolahan data pada mikrokontroler Atmega 328 seperti yang ditampilkan pada Gambar 1 .
Modem GSM yang digunakan yaitu GPRS Shield (Merk Seed Studio) yang berfungsi untuk pengiriman SMS ke nomor telepon yang diinginkan. Sedangkan Gambar 2 menampilkan GPRS Shield model SLD 33149P. Komputer merk Acer tipe Aspire 4730Z digunakan sebagai pemrograman menggunakan perangkat lunak Arduino versi 1.5.2.

\section{Metode Penelitian}

Percobaan dalam penelitian terdiri atas 4 tahap, yaitu: perancangan sistem, penentuan/pemilihan komponen, penyusunan rangkaian, dan pengujian unjuk kerja. Perancangan sistem peringatan dini kenaikan aras gas amoniak di udara terbuka melalui media SMS sebagaimana ditampilkan pada Gambar 3. Sensor gas merupakan masukan
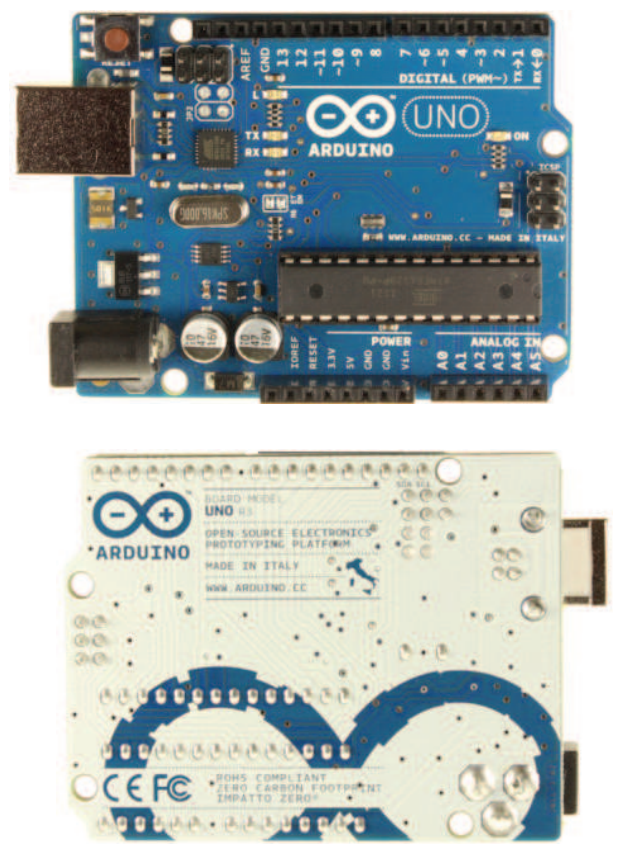

Gambar 1. Tampak depan dan tampak belakang Arduino Uno R3 (Atmel Corporation, 2009)

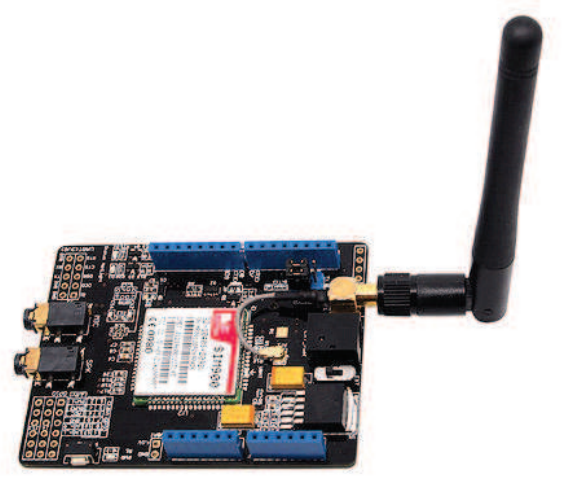

Gambar 2. GPRS Shield, model SLD33149P 


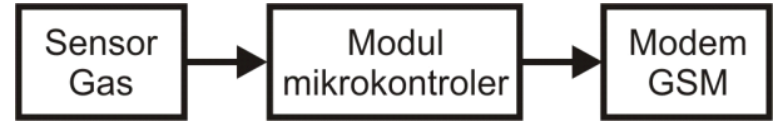

Gambar 3. Blok diagram perancangan sistem

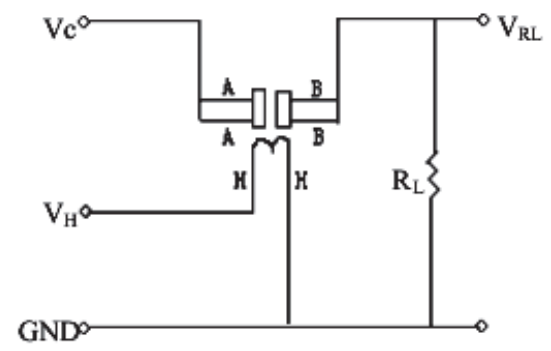

Gambar 4. Rangkaian Dasar Pengujian Sensor Gas (Shanghai Total Meter Co., Ltd., n.d.)

informasi ke sistem, modul mikrokontroler merupakan pengolah data, dan modem GSM merupakan keluaran informasi dari sistem.

Komponen utama yang harus ditentukan adalah sensor gas yang akan dipilih dan digunakan. Kemudian, modul mikrokontroler dipilih sesuai untuk mengolah data dari keluaran sensor gas. Agar keluaran sistem memberikan manfaat maka diperlukan sebuah modem GSM yang dapat menerima instruksi pengiriman SMS oleh modul mikrokontroler. Pada penelitian ini telah ditentukan penggunaan komponen sesuai dengan tujuan penelitian.

Rangkaian tambahan yang dibutuhkan untuk menggunakan sensor gas MQ137 sebagaimana ditampilkan pada Gambar 4. Kutub VH dan VC diberikan tegangan DC 5 volt dari sumber yang berbeda. Resistor RL sebesar 10 kilo-ohm, sedangkan kutub VRL dihubungkan dengan pin A0 modul mikrokontroler dan hasil pembacaan pin A0 akan diamati melalui LCD.

Secara lengkap diagram skematik rangkaian sensor hingga LCD ditampilkan pada Gambar 5. Pada bagian keluaran sensor dihubungkan dengan pin input analog $\mathrm{A} 0$ dan dibaca juga menggunakan voltmeter. Pin input analog A0 dimasukkan pada program melalui variabel sensorPin. Jalur bus data LCD dihubungkan dengan pin input digital nomor 2-5. Julur control LCD dihubungkan dengan pin input digital nomor 11 dan 12.

Koneksi antara Arduino Uno dengan

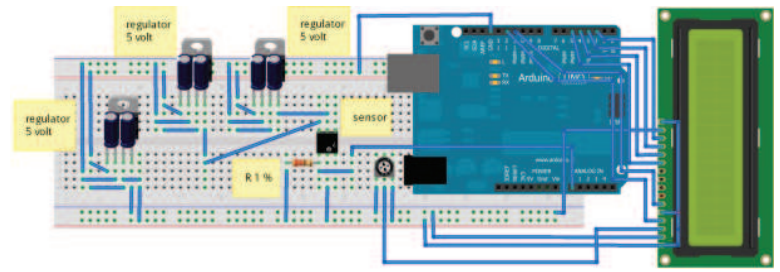

Gambar 5. Diagram skematik merangkai sensor dan modul mikrokontroler

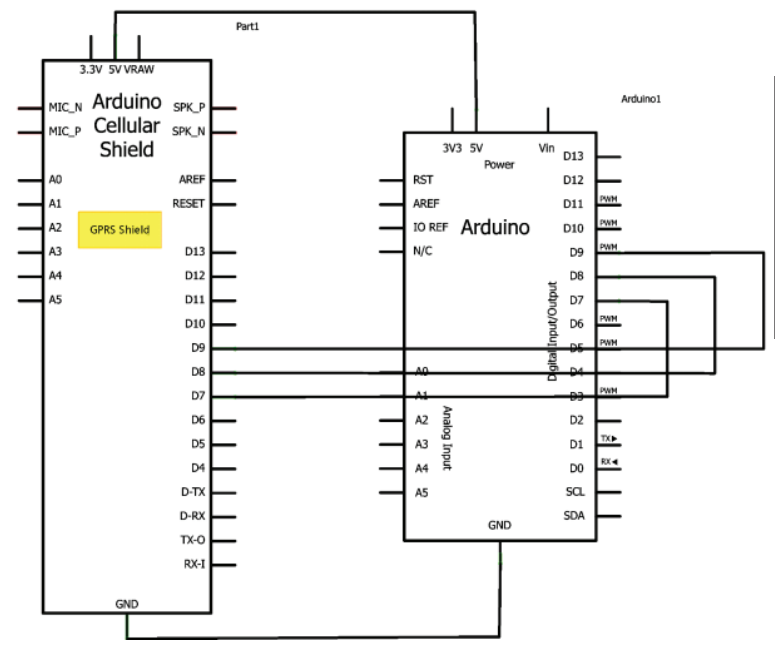

Gambar 6. Diagram skematik rangkaian GPRS Shield dengan modul mikrokontroler

GPRS Shield menggunakan jalur virtual Universal Asynchronous ReceiverTransmitter (UART)/Universal SynchronousAsynchronous Receiver-Transmitter (USART) sebagaimana ditampilkan pada Gambar 6. Hal ini dimaksudkan agar pemrograman Arduino Uno dapat didefinisikan bahwa pin digital nomor 7-9 pada Arduino Uno digunakan sebagai virtual UART/USART.

Pengujian pada setiap bagian (sensor gas dan modem GSM) dan unjuk kerja sistem dilakukan secara keseluruhan. Sensor gas dirangkai sesuai dengan skematik pada Gambar 4 dan Gambar 5 serta hasilnya dibaca melalui LCD. Pengujian modem GSM dilakukan dengan menghubungkan antara Arduino Uno dengan modem GSM sesuai dengan Gambar 6. Arduino Uno diberikan instruksi berupa Attention (At) Command untuk mengirimkan SMS kepada nomor telepon yang diinginkan.

Pengujian sistem secara keseluruhan dilakukan dengan menggabungkan rangkaian pada Gambar 5 dan Gambar 6. Sensor gas 
yang telah dipilih dipaparkan pada limbah cair yang mengeluarkan gas amoniak. Pengamatan dilakukan pada kemampuan dan kinerja sistem untuk melakukan tugas pengiriman SMS ketika aras gas amoniak yang terdeteksi melampaui ambang batas yang ditetapkan.

\section{HASIL DAN PEMBAHASAN}

\section{Hasil Pengujian Sensor Gas}

Sensor gas amoniak MQ137 yang dibuat dari tin dioxide $\left(\mathrm{SnO}_{2}\right)$ memiliki konduktivitas rendah di udara bersih. Ketika terdapat gas amoniak di udara, maka konduktivitas sensor ini naik sesuai dengan konsentrasi gas amoniak di udara. Sensor gas MQ137 memiliki sensitivitas relatif tinggi pada gas amoniak dan juga untuk senyawa organic yang mengandung amina (Shanghai Total Meter Co., Ltd., n.d.). Sensor gas amoniak MQ137 juga telah digunakan pada alat pengontrol emisi gas amoniak berbasis mikrokontroler ATmega 8535. (Heriawan, et al., 2013) Perbedaannya pada penelitian ini menggunakan Arduino Uno sebagai pengolah data.

Pengujian sensor gas amoniak MQ 137 dilakukan dengan diagram skematik sesuai dengan Gambar 4 dan Gambar 5. Ketika pada kondisi ruangan normal maka hasil pembacaan output tegangan (VRL) sekitar $0,7-0,8$ volt. Saat sensor gas amoniak MQ137 mendeteksi kenaikan konsentrasi gas amoniak yang dikeluarkan pengolahan limbah penyamakan kulit, maka terjadi kenaikan tegangan berkisar $0,3-1,5$ volt. Nilai tegangan VRL selalu berubah secara linear sesuai konsentrasi gas amoniak yang terdeteksi. Hal ini sebagaimana ditampilkan pada Gambar 7 bahwa nilai Rs/Ro merupakan rasio resistansi sensor.

Tegangan VRL maksimal dapat dicapai hingga 5 volt, karena tegangan $\mathrm{VC}$ diatur agar memberikan tegangan 5 volt sedangkan nilai tegangan VRL merupakan tegangan listrik DC analog yang menjadi keluaran sensor gas.

Keluaran sensor gas (pin VRL) dihubungkan ke pin ADC A0 pada modul mikrokontroler Arduino Uno R3. Selanjutnya hasil pembacaan ADC divisualisasi melalui LCD. Pengujian yang dilakukan (Gambar 5) memberikan hasil berupa pembacaan voltmeter dan nilai ADC sebagaimana

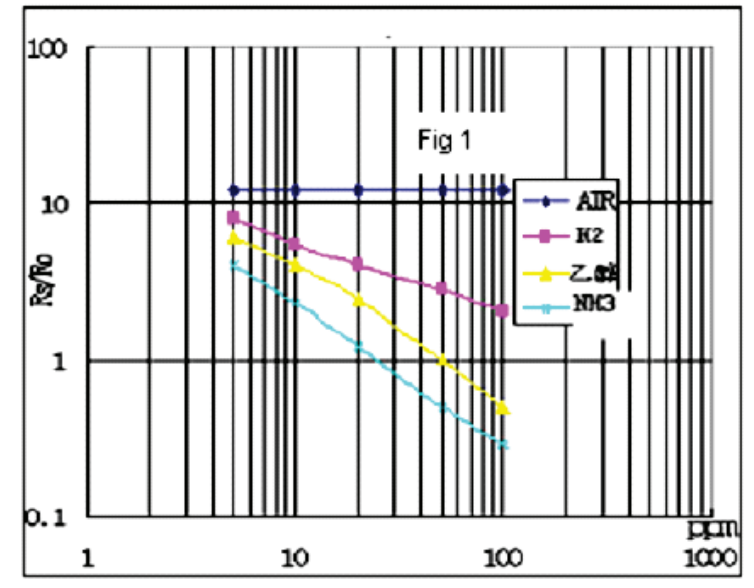

Gambar 7. Sensitivitas gas (Shanghai Total Meter Co., Ltd., n.d.)

Tabel 1. Pembacaan voltmeter dan nilai ADC

\begin{tabular}{ccl}
$\begin{array}{c}\text { Pembacaan } \\
\text { Voltmeter }\end{array}$ & $\begin{array}{c}\text { Pembacaan } \\
\text { Nilai ADC }\end{array}$ & \multicolumn{1}{c}{ Keterangan } \\
\hline $800 \mathrm{mV}$ & 160 step & Tidak dipaparkan \\
$900 \mathrm{mV}$ & 180 step & Tidak dipaparkan \\
$1391 \mathrm{mV}$ & $281 \mathrm{step}$ & Dipaparkan limbah \\
\hline
\end{tabular}

ditampilkan pada Tabel 1.

Pembacaan voltmeter dan nilai ADC memiliki keterkaitan yang dirumuskan dengan persamaan (1). Nilai 1024 didapatkan dari kuantisasi 10 bit pada ADC, sehingga 210 = 1024 step kuantisasi, maka:

pembacaan_ADC $=\frac{1024 \text { step }}{\text { tegangan_referensi }} \cdot$ pembacaan_voltmeter

Nilai tegangan referensi pada persamaan (1) adalah 5 volt, karena mikrokontroler bekerja pada tegangan 5 volt dan menjadi nilai tegangan standar dari sinyal digital. Sehingga persamaan (1) diubah menjadi:

pembacaan_ADC $=\frac{1024 \text { step }}{5 \text { volt }} \cdot$ pembacaan_voltmeter

Berdasarkan persamaan (2) dapat disimpulkan bahwa keterkaitan antara tegangan VRL (pembacaan voltmeter) dan nilai ADC adalah linear, sehingga nilai ADC juga linear terhadap konsentrasi gas amoniak yang terdeteksi.

Berdasarkan Tabel 1, disajikan nilai ADC 180 berarti aras gas amoniak di udara 
bebas masih dalam batas normal sedangkan nilai ADC 281 menunjukkan aras gas amoniak sudah melewati ambang batas. Agar sistem peringatan dini memiliki sensitivitas yang baik, maka ditentukan nilai ADC yang menjadi ambang batas $=200$. Nilai ambang batas $=200$ dideklarasikan pada saat pemrograman melalui variabel ambang batas.

Pada Gambar 8 menampilkan instruksi yang harus dituliskan untuk membaca ADC pada channel tertentu dan menampilkannya melalui LCD. Instruksi digunakan untuk menampilkan karakter pada LCD diawali dengan "lcd.". Instruksi "sensorValue= analogRead(sensorPin);" dimana nilai variable sensorPin $=\mathrm{A} 0$, sehingga instruksi tersebut menjadi "sensorValue=analogRead (A0);". Instruksi tersebut digunakan untuk melakukan proses konversi tegangan analog dari tegangan keluaran sensor yang masuk melalui pin A0 dan nilai ADC disimpai melalui variabel sensorValue. Instruksi "lcd.print(sensorValue)" digunakan untuk menampilkan pada LCD nilai ADC yang tersimpan di variabel sensorValue. Instruksi "delay(800);" yaitu mengalihkan jalannya program untuk menghitung waktu sebanyak $800 \mathrm{mS}$. Hal ini berfungsi agar perubahan pembacaan pada ADC dapat diamati dan dicatat.

\section{Hasil Pengujian Modem GSM}

GPRS Shield ini dikombinasikan dengan modul Arduino Uno dengan konfigurasi tumpukan. Komunikasi antara GPRS Shield dengan Arduino Uno dapat dilakukan dengan 2 cara yaitu jalur perangkat keras UART/USART ataupun jalur virtual

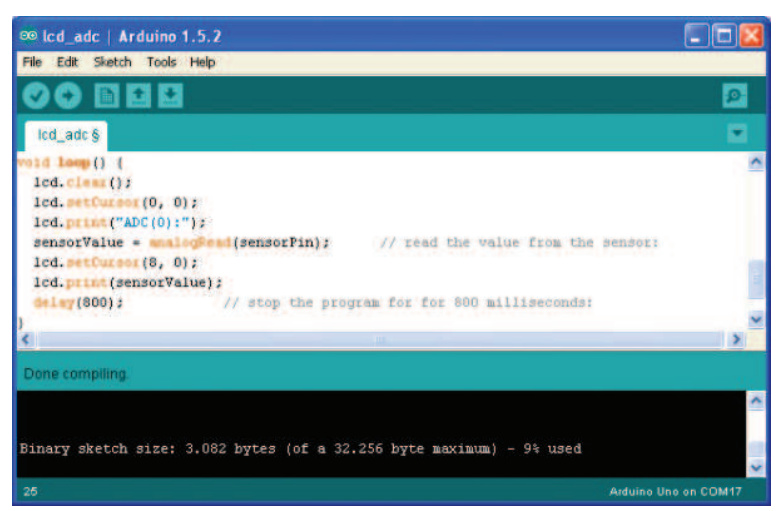

Gambar 8. Cuplikan program pembacaan ADC dan penampilan di LCD
UART/USART. Pada penelitian ini dipilih cara yang kedua sehingga jalur perangkat keras UART/USART masih dapat digunakan untuk keperluan lain. Dengan demikian koneksi yang dibutuhkan antara Arduino Uno dan GPRS Shield seperti pada Gambar 6. Sambungan 5 volt dan ground digunakan sebagai catu daya GPRS Shield, adapun pin 7 dan pin 8 Arduino Uno digunakan sebagai jalur komunikasi virtual UART/USART. keras UART/USART ataupun jalur virtual UART/USART. Pada penelitian ini dipilih cara yang kedua sehingga jalur perangkat keras UART/USART masih dapat digunakan untuk keperluan lain. Dengan demikian koneksi yang dibutuhkan antara Arduino Uno dan GPRS Shield seperti pada Gambar 6. Sambungan 5 volt dan ground digunakan sebagai catu daya GPRS Shield, adapun pin 7 dan pin 8 Arduino Uno digunakan sebagai jalur komunikasi virtual UART/USART.

Untuk mengirimkan SMS, maka Arduino Uno memberikan instruksi berupa At command. Instruksi At command diberikan Arduino Uno dalam bentuk data serial sehingga seluruh At command dimasukkan ke dalam instruksi "mySerial.print(...);" atau "mySerial.println(...);". Pengujian GPRS shield berupa pengiriman SMS dengan instruksi yang berikan dari Arduino Uno seperti disajikan pada Gambar 9.

Proses yang dilalui untuk mengirimkan SMS menggunakan GPRS Shield terdiri dari 4 proses, yaitu:

1. Instruksi At command "AT+CMGF=1" digunakan untuk mengatur GPRS Shield

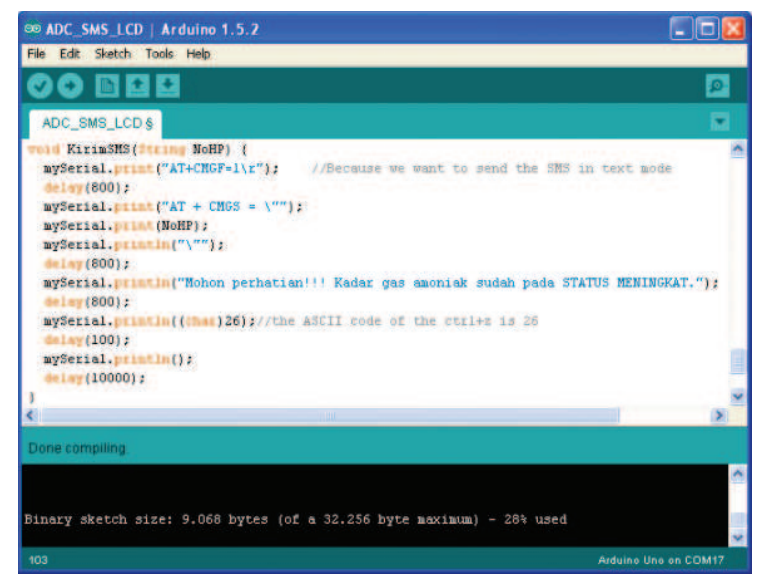

Gambar 9. Instruksi untuk mengirim SMS 
untuk menjalankan modus pengiriman SMS.

2. Instruksi At command "AT+CMGS= $\backslash$ NoHP $\backslash$ " digunakan untuk mengatur GPRS Shield untuk menuliskan nomor telepon yang akan dikirim SMS. Variabel NoHP berisi nomor telepon yang dideklarasikan pada awal program.

3. Instruksi diantara dua petik digunakan untuk menuliskan informasi yang dikirim melalui SMS.

4. Instruksi "(char)26" digunakan untuk mengakhiri informasi yang dikirim melalui SMS.

Setelah 4 proses di atas dilalui, maka GPRS Shield akan mengirimkan SMS pada nomor telepon yang telah dideklarasikan.

Diantara instruksi At command diberi jeda dengan instruksi "delay(...);" karena GPRS shield membutuhkan waktu untuk menerima dan memahami instruksi yang diberikan melalui virtual UART/USART. Apabila instruksi yang diberikan terlalu cepat, maka instruksi tersebut tidak dapat dijalankan seluruhnya dengan baik.

\section{Unjuk Kerja Sistem}

Setelah penentuan spesifikasi dan dilakukan perancangan awal, maka langkah selanjutnya dibuat flow chart dalam bentuk yang sederhana, yaitu sebuah program yang terdiri atas beberapa sub-rutin. Setiap subrutin diwujudkan dalam bentuk flow chart. (Park, 2003). Gambar 10 menampilkan flow chart program sistem peringatan dini berbasis SMS. Setiap tahap proses ditampilkan status program dalam LCD dan hal ini akan lebih mempermudah dalam pengecekan tahap dan jalannya program.

Implementasi flow chart pada Gambar 10 menjadi sekumpulan instruksi yang ditulis dalam perangkat lunak Arduino versi 1.5.2 seperti disajikan pada Gambar 11 yang memiliki beberapa sub-rutin yang telah dijelaskan pada Gambar 9.

Instruksi yang digunakan untuk memantau apakah aras gas amoniak di udara bebas telah melewati ambang batas yaitu instruksi "if(baca input>ambang batas)". Artinya apakah variabel baca input nilainya sudah lebih besar daripada variabel

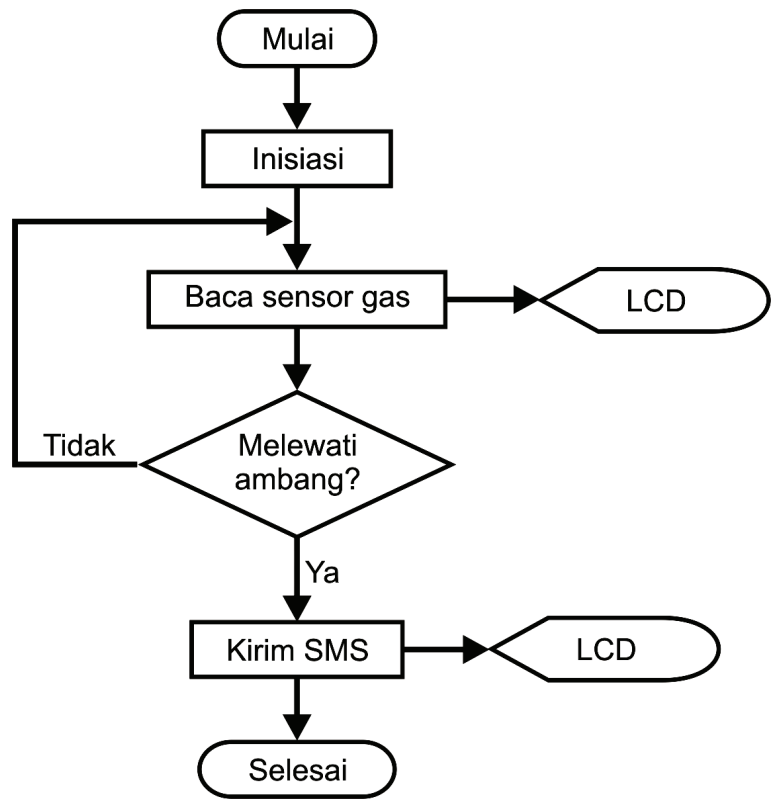

Gambar 10. Flow chart sistem peringatan dini berbasis SMS

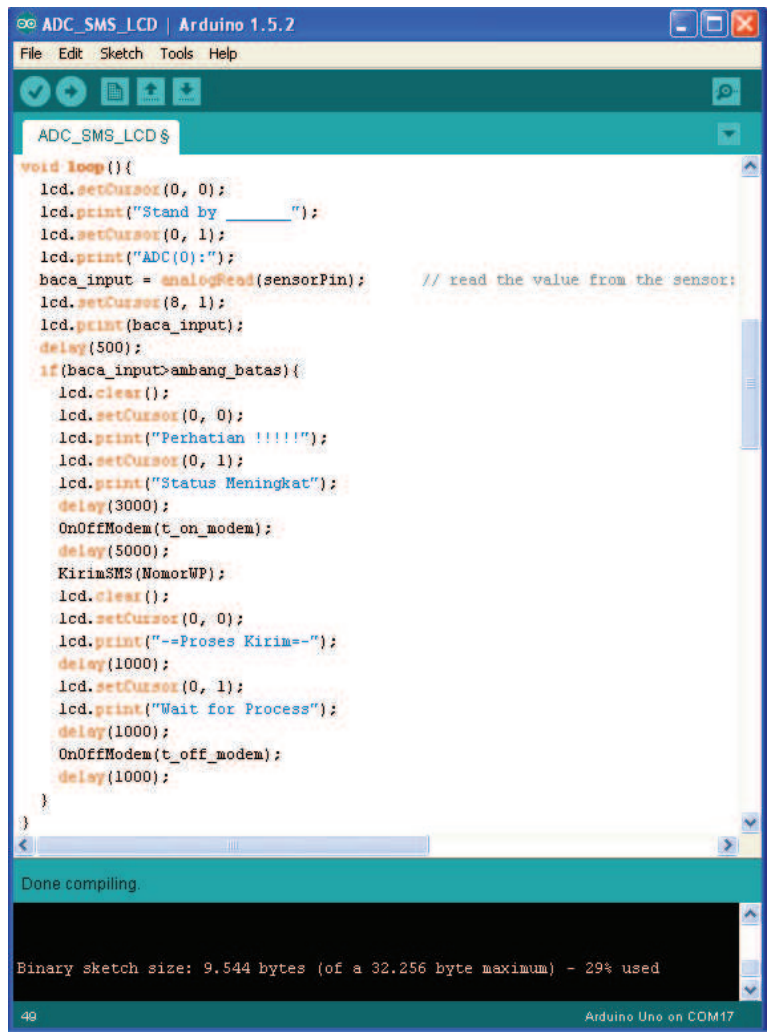

Gambar 11. Program sistem peringatan dini berbasis SMS

ambang_batas. Apabila syarat tersebut terpenuhi, maka dijalankan instruksi selanjutnya. Apabila syarat tidak terpenuhi, maka kembali menjalankan pemantauan aras gas amoniak di udara bebas. 


\section{KESIMPULAN DANSARAN}

\section{Kesimpulan}

Sensor gas amoniak MQ137 merupakan detektor yang mampu memberikan hasil pembacaan secara linear sebanding dengan konsentrasi gas amoniak yang dideteksi. Keluaran MQ137 berupa tegangan DC analog yang mengalami kenaikan tegangan $0,3-1,5$ volt apabila konsentrasi gas amoniak yang keluar dari pengolahan limbah penyamakan kulit meningkat. Nilai tegangan tersebut dapat langsung di-digital-kan melalui 1 channel ADC pada Arduino Uno R3. Nilai ADC yang tepat sebagai ambang batas gas amoniak yaitu 200. Apabila nilai keluaran MQ137 melebihi ambang batas, maka Arduino Uno akan memberikan instruksi berupa At command kepada GPRS Shield untuk mengirimkan SMS kepada nomor yang diinginkan. SMS yang dikirimkan berisi informasi bahwa kadar gas amoniak melebihi ambang batas.

\section{Saran}

Pengembangan penelitian ini dalam pencarian metode yang tepat untuk melakukan kalibrasi sensor gas amoniak MQ137.

\section{UCAPAN TERIMA KASIH}

Penulis mengucapkan terima kasih kepada tim in house research Balai Besar Kulit, Karet, dan Plastik, yaitu: Prayitno, Sri Sutyasmi, Eko Sulistiyo Wibowo, Muhammad Sholeh, Christiana Herry Purwanti, dan Iwan Fajar Pahlawan atas bantuan dan kerjasama selama pelaksanaan penelitian ini.

\section{DAFTAR PUSTAKA}

Atmel Corporation, 2009, Atmel 8-bit AVR Microcontroller with 4/8/16/32K Bytes In-System Programmable Flash ATmega48PA, ATmega88PA, ATmegal68PA, ATmega328P, http://www.atmel.com/Images/doc8161 .pdf, diakses pada 26 Juni 2012.

Bendahan M., Lauque P., Seguin J.L., Aguir K. dan Knauth P., 2003, Development of an ammonia gas sensor, Sensors and Actuators B, 95: 170-176.

Calcutt D., Cowan F. and Parchizadeh H., 2004, 8051 Microcontrollers An
Applications-Based Introduction, Elsevier Ltd., Oxford.

Shanghai Total Meter Co., Ltd., n.d., MQ137 Semiconductor Sensor for Ammonia, http://www.chinatotal.com/Product/met er/gas-sensor/MQ137.pdf, diakses pada 26 Juni 2012.

dit Picard C.L.E., Bernicot Y., Merdrignac O. and Guyader J., 1997, Detection of $\mathrm{NH}_{3}$ and $\mathrm{H}_{2} \mathrm{~S}$ with thick film semiconductor sensors based on $\mathrm{Cd} 2 \mathrm{xGeO} 4 \mathrm{x} 3 \mathrm{yN} 2 \mathrm{y}$ oxynitrides, Sensor and Actuators B, 42: 47-51.

Heriawan, R., Suciati, S.W. dan Supriyanto, A., 2013, Alat pengontrol emisi gas amonia $\left(\mathrm{NH}_{3}\right)$ di peternakan ayam berbasis mikrokontroler Atmega 8535 menggunakan sensor gas MQ-137, Jurnal Teori dan Aplikasi Fisika, 01 (01): 69-73.

Ibrahim, D., 2010, SD card projects using the PIC microcontroller, Elsevier Ltd., Oxford.

Kato, Y., 2010, Splish: a visual programming environment for arduino to accelerate physical computing experiences, Eighth International Conference on Creating, Connecting and Collaborating through Computing, Musashi University, Tokyo.

Menteri Negara Lingkungan Hidup, 2010, Peraturan Menteri Negara Lingkungan Hidup nomor 12 tahun 2010 tentang pelaksanaan pengendalian pencemaran udara di daerah,

Mustaqim I., Rivai M., Purwanto D. dan Tasripan, 2010, Pengukuran tingkat gas polutan pada udara menggunakan tabung detektor gas dengan bantuan kamera, Jurnal Seminar Teknik Elektro ITS Surabaya, 1: 1-5.

Park, J., 2003, Practical embedded controllers design and troubleshooting with the Motorolla 68HC11, Elsevier Ltd., Oxford.

Song, Z., Williams, C. J. and Edyvean, R. G. J., 2004, Treatment of tannery wastewater by chemical coagulation, Desalination, 164: 245-259.

Teikari P., Najjar R.P., Malkki H., Knoblauch K., Dumortier D., Gronfier C., and Cooper H.M., 2012, An inexpensive Arduino-based 
LED stimulator system for vision research, Journal of Neuroscience Methods, 211:227-236.

Timmer, B., Olthuis W., and van den Berg A., 2005, Ammonia sensors and their application: a review, Sensors and Actuators B, 107: 666677

Wheat, D. 2011, Arduino Internals, Apress, New York. 